\title{
Rethinking diagnostic delay in cancer: how difficult is the diagnosis?
}

\author{
(9) (1) $(9)$ OPEN ACCESS
}

Georgios Lyratzopoulos, Jane Wardle, and Greg Rubin argue that delays in referral for suspected cancer are unlikely to be caused by poor professional performance and explore other potential causes and strategies for improvement

\section{Georgios Lyratzopoulos clinical senior research associate ${ }^{1}$, Jane Wardle professor of clinical psychology ${ }^{2}$, Greg Rubin professor of general practice and primary care ${ }^{3}$}

\footnotetext{
Cambridge Centre for Health Services Research, Department of Public Health and Primary Care, University of Cambridge, Cambridge CB2 0SR, UK; ${ }^{2}$ Health Behaviour Research Centre, University College London, London, UK; ${ }^{3}$ School of Medicine, Pharmacy and Health, University of Durham, Durham, UK
}

The timely diagnosis of cancer is a frequent theme in the lay press and an increasingly common topic for quality improvement initiatives. $^{12}$

The UK's health secretary has advocated ranking general practices on the NHS Choices website according to how promptly patients subsequently diagnosed with cancer are referred to specialist services for suspected cancer. ${ }^{3}$ But is such a policy based on evidence? Its main assumption is that the multiple visits made by these patients to primary care before referral chiefly reflect poor professional performance rather than factors such as clinical complexity, reasonable watchful waiting, or the need for appropriate investigations in primary care. We review the occurrence of multiple pre-referral consultations and discuss how a better understanding of variation between cancers might improve the timeliness of diagnosis.

\section{How common are multiple consultations?}

Most patients with cancer present to primary care with symptoms that have low or very low positive predictive values. Even "red flag" symptoms (such as rectal bleeding, dysphagia, haemoptysis, and haematuria) have positive predictive values for cancer of $<10 \%$ in men, ${ }^{4}$ and these values are typically up to twofold lower for women and even lower for young adults and children $(<1 \%){ }^{5}$ This means that the great majority of patients with such symptoms will not have cancer.

Despite the low specificity of cancer symptoms, about $80 \%$ of patients subsequently diagnosed with cancer are referred to a hospital specialist after one (50\%) or two (30\%) consultations. ${ }^{67}$ But a substantial minority (20\%) of patients with cancer visit a primary care doctor with relevant symptoms three or more times before referral. This number is often considered by policy makers and cancer charities to reflect an avoidable delay. ${ }^{89}$ In this article we use the term "multiple consultations" to denote three or more visits to primary care before referral.

\section{Why multiple consultations matter}

The number of consultations is associated with increased time from presentation to referral for cancer. National audit data show that the median time to referral is 34 days for patients having three consultations, 47 days for four consultations, and 96 days for five or more consultations. ${ }^{6}$ However, these interval data are skewed to the right, meaning that many patients experience notably longer times to referral-for example, a quarter of patients with three, four, and five or more consultations experience intervals longer than 64, 90, and 172 days, respectively.

Stage at diagnosis is a strong predictor of survival, so prolonging the interval from presentation to diagnosis could increase the risk of stage progression and poorer clinical outcomes..$^{10} 11$ However, confounding by patients with rapidly progressive disease who present with advanced cancer and have poor outcomes despite prompt referral makes the interpretation of observational studies challenging. ${ }^{12}$

Multiple consultations also adversely affect the experience of care as patients with cancer and their relatives express strong preferences for a prompt diagnosis. ${ }^{8}{ }^{13}$ Not suspecting the diagnosis of cancer, or failing to act on such a suspicion, can also be upsetting for doctors.

\section{Why do multiple consultations occur?}

Considering different cancers separately is critical for gaining insight into the challenges of diagnosis. Although often referred 
to as a single entity, cancer is a highly heterogeneous disease, arising from different organs and systems and associated with diverse symptoms.

National audit and patient survey data show that the strongest predictor of multiple consultations is tumour site. Between $30 \%$ and $50 \%$ of patients subsequently diagnosed with multiple myeloma or pancreatic, stomach, or lung cancer have multiple consultations, compared with $<10 \%$ of patients subsequently diagnosed with breast cancer or melanoma (figure $\downarrow$ ). ${ }^{67}$ These differences seem to reflect the "symptom signature" of different cancers-cancers where most patients present with fairly specific symptoms (such as a palpable breast lump or a visible skin lesion) are less associated with multiple consultations than those where most patients present with non-specific symptoms (such as back or abdominal pain). The proportion of patients with a given cancer who experience multiple consultations could therefore be considered a marker of the difficulty of suspecting that cancer at first presentation to primary care.

Another relevant factor is the need for initial investigations for non-specific symptoms in primary care. This is good clinical practice but often requires additional consultations to discuss the results and to plan the next steps. ${ }^{14}$ In the English National Audit of Cancer Diagnosis in Primary Care about $80 \%$ of patients with multiple consultations had at least one diagnostic test-twice the proportion of patients who were referred after a single consultation.

Factors unrelated to the quality of clinical reasoning during the consultation may also be implicated. A recent study of significant event audits in the diagnosis of lung cancer revealed several such factors, including poor communication between primary and secondary care services and patient preference for delayed referral.

If poor medical practice were the main reason for multiple consultations, they might be expected only in patients consulting a minority of clinicians. But given that up to $20 \%$ of all patients with newly diagnosed cancer in England have multiple consultations, it seems improbable that these thousands of patients are seen by a few poorly performing GPs.

Considered together, these observations suggest that diagnostic difficulty and the need for investigation of poorly differentiated symptoms in primary care are more likely to be the drivers for multiple consultations than poor diagnostic reasoning and suboptimal professional practice.

\section{Diagnostic difficulty}

The association between cancer site and multiple consultations led us to question whether individual cancers could be classified by diagnostic difficulty. If so, this knowledge might help to guide the development of tests and interventions for decision support and quality improvement, providing a useful framework to guide future practice, policy, and research. ${ }^{15}$ Using the proportion of patients who have multiple consultations as a measure of diagnostic difficulty, cancers can be divided into those that are harder to suspect ( $>30 \%$ of patients), easier to suspect $(<10 \%)$, and those of intermediate diagnostic difficulty $(10-30 \%)$ (table $\Downarrow$ ).

\section{Harder to suspect cancers}

Most patients with these cancers present with non-specific symptoms that are often seen in primary care. For example, two thirds of patients with multiple myeloma present with back pain, ${ }^{16}$ and nearly half of patients with pancreatic cancer with abdominal pain. ${ }^{17}$
Breakthroughs in diagnostic technology and the more frequent and systematic use of existing tests could be particularly useful in shortening the interval to referral for patients with these cancers (table $\downarrow$ ). For example, diagnosis of multiple myeloma might be improved by a point of care (finger prick) test currently in early clinical application, which detects immunoglobulin free light chains,${ }^{18}$ or by greater use of existing blood tests, such as those for inflammatory markers including plasma viscosity. ${ }^{19}$ For pancreatic cancer, tests that measure microRNA levels in blood are being explored. ${ }^{20}$ Another approach is to make imaging technologies, such as ultrasonography for abdominal complaints, more accessible at the point of care. ${ }^{21}$ Novel diagnostic tests will need careful evaluation, ideally in pragmatic randomised controlled trials in primary care.

\section{Easier to suspect cancers}

These cancers (for example, breast, endometrial, or testicular cancer) are of lower diagnostic difficulty because most patients present with fairly specific signs and symptoms.

However, some patients experience multiple consultations for reasons that are not entirely clear but are likely to include atypical presentations, personal preference for delayed referral, and suboptimal clinical reasoning or other healthcare factors. ${ }^{1}$ When patients who had multiple consultations are subsequently diagnosed with easier to suspect cancers, quality improvement approaches, such as significant event audits, should be triggered to help understand the factors responsible and to identify opportunities for improvement (table $\downarrow$ ).

\section{Intermediate cancers}

Some patients with cancers in the intermediate category of diagnostic difficulty (such as colorectal and renal cancers) have specific symptoms but others present atypically. The interventions that could be helpful for this category of cancers are potentially useful for all cancers. Decision support interventions may be of particular value..$^{22}$ Enabling access to specialist expertise or investigations (such as imaging and endoscopy) may also be particularly helpful, and can be supported by case discussion arrangements with specialists. In a national primary care audit, GPs judged that better access to investigations would have altered management in $8-20 \%$ of patients subsequently diagnosed with cancers for which endoscopy or imaging are the principal diagnostic modalities, such as abdominal organ cancers. ${ }^{6}$

\section{Potential indirect benefits and harms}

Incidental diagnosis of asymptomatic lesions of uncertain prognosis may occur in symptomatic patients who have imaging investigations for suspected cancer, with unclear patient benefit. ${ }^{23}$ On the other hand, investigations in some patients with suspected cancer will enable diagnosis of other diseases that are causing the symptoms (for example, inflammatory bowel disease diagnosed as a result of tests for suspected colorectal cancer), and these patients will benefit from timely and accurate diagnosis and treatment. A better understanding is needed of the potential for indirect benefits and harms from tests for symptomatic patients, bearing in mind that most patients express a preference to be investigated for potential cancer at risk levels as low as $1 \%,{ }^{24}$ which is well below current detection rates of about $10 \%$ among patients referred for suspected cancer. ${ }^{25}$ 


\section{Cancer policy and research}

Efforts to reduce multiple consultations should not deflect attention from opportunities to shorten diagnostic intervals that may lie either with the patient before presentation or with secondary care after referral. For example, the time from symptom onset to first presentation is longer than a month for a quarter of women later diagnosed with breast cancer, compared with an average interval to referral after presentation of zero days. ${ }^{62}$ Avoidable delays after referral have been reported for patients later diagnosed with colorectal cancer-in a US study the median time from first referral to completion of colonoscopy was 123 days, ${ }^{27}$ although relevant UK evidence is currently sparse.

When cancer is suspected but symptoms are non-localising, new models of multispecialty diagnostic services can help to integrate diagnostic assessment processes and minimise prolonged investigation intervals or the risk of referral to the "wrong" specialty. Such services have been recently established in Denmark and are being piloted in England through the Accelerate Coordinate Evaluate (ACE) NHS initiative. Any new interventions or diagnostic service models need to be evaluated using rigorous study designs in primary care populations.

Examining variation in measures of diagnostic activity (such as use of endoscopy or imaging) across general practices might provide insight into how to improve diagnostic quality. ${ }^{28} 29$ Improving the diagnostic process requires the development of failsafe systems for overlooked abnormal tests and recall of patients who did not attend planned investigations or follow-up appointments. $^{30} 31$

Substantial advances in surgical safety have been made by considering the performance of theatre teams and hospital systems in addition to the competency of individual surgeons. ${ }^{32}$ Similarly, research to improve diagnostic timeliness should encompass system-wide factors, including communication between primary and secondary care.

We argue that prolonged diagnostic intervals chiefly reflect limitations in scientific knowledge and in the organisation and delivery of healthcare. This understanding is critical for informing the development of novel research strategies and policies to improve diagnostic quality. We advocate a framework for future research and improvement strategies that recognises the central role of variation in diagnostic difficulty across different cancers and organisational factors. We also advocate better information for the public, the media, and policy makers about the origins of prolonged intervals between presentation and diagnosis of cancer.

GL is supported by a postdoctoral fellowship award from the National Institute for Health Research 2012-14 (PDF-2011-04-047). JW is supported by Cancer Research UK. The views expressed in this publication are those of the authors and not necessarily those of the NHS, the National Institute for Health Research, the Department of Health, or any other organisation.

Contributors and sources: The article was developed iteratively through discussions between the authors, who work in public health and clinical epidemiology (GL), behavioural science (JW), and primary care and general practice research (GR). All authors contributed to the arguments and the proposed stratification framework. GL is the guarantor.

Competing interests: We have read and understood BMJ policy on declaration of interests and declare the following interests: GL is a member (2012-15) of NICE's development group for the guideline on the recognition and management of suspected cancer in children, young people and adults; the arguments made in this paper are the product of academic research unrelated to the scope of the guideline. GR led the National Audit of Cancer Diagnosis in Primary Care on behalf of the Royal College of General Practitioners in 2010-12 and was the RCGP Clinical Lead for Cancer between 2012 and March 2014. JW has no relevant interests to declare.

Provenance and peer review: Not commissioned; externally peer reviewed.

1 Mitchell ED, Rubin G, Macleod U. Understanding diagnosis of lung cancer in primary care: qualitative synthesis of significant event audit reports. Br J Gen Pract 2013;63:e37-46.

2 Leaver L, Gilbert BJ, Jones J, Allaby M. Cancer referrals. Cancer cases diagnosed as emergencies may be fewer than reported. BMJ 2013;347:44773.

3 Malnick, E. GPs to be named and shamed over cancer diagnosis. Telegraph 2014 Jun 29. www.telegraph.co.uk/health/healthnews/10933442/GPs-to-be-named-and-shamedover-cancer-diagnosis.html.

4 Jones R, Latinovic R, Charlton J, Gulliford MC. Alarm symptoms in early diagnosis of cancer in primary care: cohort study using General Practice Research Database. BMJ 2007;334:1040.

5 Dommett RM, Redaniel MT, Stevens MC, Hamilton W, Martin RM. Features of cancer in teenagers and young adults in primary care: a population-based nested case-control study. Br J Cancer 2013;108:2329-33.

6 Lyratzopoulos G, Abel GA, McPhail S, Neal RD, Rubin GP. Measures of promptness of cancer diagnosis in primary care: secondary analysis of national audit data on patients with 18 common and rarer cancers. Br J Cancer 2013;108:686-90.

7 Lyratzopoulos G, Neal RD, Barbiere JM, Rubin GP, Abel GA. Variation in number of general practitioner consultations before hospital referral for cancer: findings from the 2010 National Cancer Patient Experience Survey in England. Lancet Oncol 2012;13:353-65.

8 Rarer Cancers Foundation. Primary cause? An audit of the experience in primary care of rarer cancer patients. 2011. www.rarercancers.org.uk/images/stories/cdf/p8and9/ primary\%20cause\%20-\%20final.pdf.

9 Royal College of General Practitioners. National audit of cancer diagnosis in primary care. 2011. www.rcgp.org.uk/news/2011/november/ /media/Files/News/National_Audit_of_ Cancer_Diagnosis_in_Primary-Care.ashx.

10 Richards MA, Westcombe AM, Love SB, Littlejohns P, Ramirez AJ. Influence of delay on survival in patients with breast cancer: a systematic review. Lancet 1999;353:1119-26.

11 Tørring ML, Frydenberg M, Hamilton W, Hansen RP, Lautrup MD, Vedsted P. Diagnostic interval and mortality in colorectal cancer: U-shaped association demonstrated for three different datasets. J Clin Epidemiol 2012;65:669-78.

12 Neal RD. Do diagnostic delays in cancer matter? Br J Cancer 2009;101(Suppl 2):S9-12.

13 Risberg T, Sørbye SW, Norum J, Wist EA. Diagnostic delay causes more psychological distress in female than in male cancer patients. Anticancer Res 1996;16:995-9.

14 National Institute for Health and Care Excellence. Referral guidelines for suspected cancer. 2005. www.nice.org.uk/guidance/cg27.

15 Graber ML. Medical diagnosis-the promise. Diagnosis 2014;1:5-9.

16 Howell DA, Smith AG, Jack A, Patmore R, Macleod U, Mironska E, et al. Time-to-diagnosis and symptoms of myeloma, lymphomas and leukaemias: a report from the Haematological Malignancy Research Network. BMC Hematol 2013;13:9.

17 Stapley S, Peters TJ, Neal RD, Rose PW, Walter FM, Hamilton W. The risk of pancreatic cancer in symptomatic patients in primary care: a large case-control study using electronic records. Br J Cancer 2012;106:1940-4.

18 University of Birmingham. World's first point-of-care diagnostic device for multiple myeloma. 2013. www.birmingham.ac.uk/partners/news/items/worlds-first-point-of-care-diagnosticdevice-for-multiple-myeloma.aspx.

19 Bird JM, Owen RG, D'Sa S, Snowden JA, Pratt G, Ashcroft J, et al. Guidelines for the diagnosis and management of multiple myeloma 2011. Br J Haematol 2011;154:32-75.

20 Schultz NA, Dehlendorff C, Jensen BV, Bjerregaard JK, Nielsen KR, Bojesen SE, et al. MicroRNA biomarkers in whole blood for detection of pancreatic cancer. JAMA 2014;311(4):392-404.

21 Moore CL, Copel JA. Point-of-care ultrasonography. N Engl J Med 2011;364:749-57.

22 Hamilton W, Green T, Martins T, Elliott K, Rubin G, Macleod U. Evaluation of risk assessment tools for suspected cancer in general practice: a cohort study. Br J Gen Pract 2013;63:e30-6.

23 Guldbrandt LM, Rasmussen TR, Rasmussen F, Vedsted P. Implementing direct access to low-dose computed tomography in general practice-method, adaption and outcome. PLoS One 2014;9:e112162.

24 Banks J, Hollinghurst S, Bigwood L, Peters TJ, Walter FM, et al. Preferences for cancer investigation: a vignette-based study of primary-care attendees. Lancet Oncol 2014; $15: 232-40$

25 Meechan D, Gildea C, Hollingworth L, Richards MA, Riley D, Rubin G. Variation in use of the 2-week referral pathway for suspected cancer: a cross-sectional analysis. $\mathrm{Br} J \mathrm{Gen}$ Pract 2012;62:e590-7.

26 Keeble S, Abel GA, Saunders CL, McPhail S, Walter FM, Neal RD, et al. Variation in promptness of presentation among 10297 patients subsequently diagnosed with one of 18 cancers: evidence from a National Audit of Cancer Diagnosis in Primary Care. Int $\mathrm{J}$ Cancer 2014;135:1220-8.

27 Singh H, Khan R, Giardina TD, Paul LW, Daci K, Gould M, et al. Postreferral colonoscopy delays in diagnosis of colorectal cancer: a mixed-methods analysis. Qual Manag Health Care 2012;21:252-61.

28 National Cancer Intelligence Network of Public Health England. General practice profiles. www.ncin.org.uk/cancer_information_tools/profiles/gp_profiles.

29 Rogers S, Gildea C, Meechan D, Baker R. Access, continuity of care and consultation quality: which best predicts urgent cancer referrals from general practice? J Public Health (Oxf) 2014;36:658-66.

30 Singh H, Giardina TD, Petersen LA, Smith MW, Paul LW, Dismukes K, et al. Exploring situational awareness in diagnostic errors in primary care. BMJ Qual Saf 2012;21:30-8.

31 Murphy DR, Laxmisan A, Reis BA, Thomas EJ, Esquivel A, Forjuoh SN, et al. Electronic health record-based triggers to detect potential delays in cancer diagnosis. BMJ Qual Saf 2014;23:8-16. 


\section{Key messages}

Most patients who have cancer diagnosed after the onset of symptoms are referred after one or two GP consultations ( $80 \%)$, but a substantial minority $(20 \%)$ have three or more consultations

Multiple GP consultations prolong diagnostic intervals and may affect clinical outcomes and care experience

The proportion of patients who have multiple consultations varies by cancer site, consistent with variation in each cancer's symptom signature, with some cancers being harder to suspect than others

Diagnostic difficulty and the need for investigations in primary care could contribute substantially to the risk of multiple consultations

Diagnosis may be swifter if facilitated by decision support interventions, better interactions between generalists and specialists, and easier access to diagnostics

Policy initiatives focusing solely on professional performance are unlikely to be effective

32 Vincent C, Moorthy K, Sarker SK, Chang A, Darzi AW. Systems approaches to surgical quality and safety: from concept to measurement. Ann Surg 2004;239:475-82.

Accepted: 12 November 2014

Cite this as: BMJ 2014;349:g7400

\section{Related links}

\section{thebmj.com}

- Read more analysis articles from The BMJ

This is an Open Access article distributed in accordance with the Creative Commons Attribution Non Commercial (CC BY-NC 4.0) license, which permits others to distribute, remix, adapt, build upon this work non-commercially, and license their derivative works on different terms, provided the original work is properly cited and the use is non-commercial. See: http://creativecommons.org/licenses/by-nc/4.0/. 


\section{Table}

Table 1| How interventions to improve diagnostic timeliness might be applied to cancers in different diagnostic difficulty categories

\begin{tabular}{lll} 
Category & Definition & Diagnostic support interventions \\
Harder to suspect & $\begin{array}{l}\text { Most patients present with non-specific symptoms (eg, } \\
\text { multiple myeloma, pancreas, stomach, lung) }\end{array}$ & $\begin{array}{l}\text { Increased research investment in development of novel point of } \\
\text { care tests and greater use of existing tests }\end{array}$ \\
\hline Intermediate* $^{*}$ & $\begin{array}{l}\text { Some patients present with specific symptoms, but others } \\
\text { present atypically (eg, colon, renal, lymphoma) }\end{array}$ & $\begin{array}{l}\text { Better decision support during consultation integrated with } \\
\text { electronic health records. Wider access to diagnostic tests and } \\
\text { specialist advice }\end{array}$ \\
\hline Easier to suspect & Most patients present with highly specific symptoms or signs & $\begin{array}{l}\text { Quality improvement interventions, including significant event } \\
\text { audits and root cause analysis }\end{array}$ \\
\hline
\end{tabular}

*The association of interventions with diagnostic difficulty categories is not absolute-for example, patients with cancers of intermediate diagnostic difficulty can also benefit from novel diagnostic tests. 


\section{Figure}

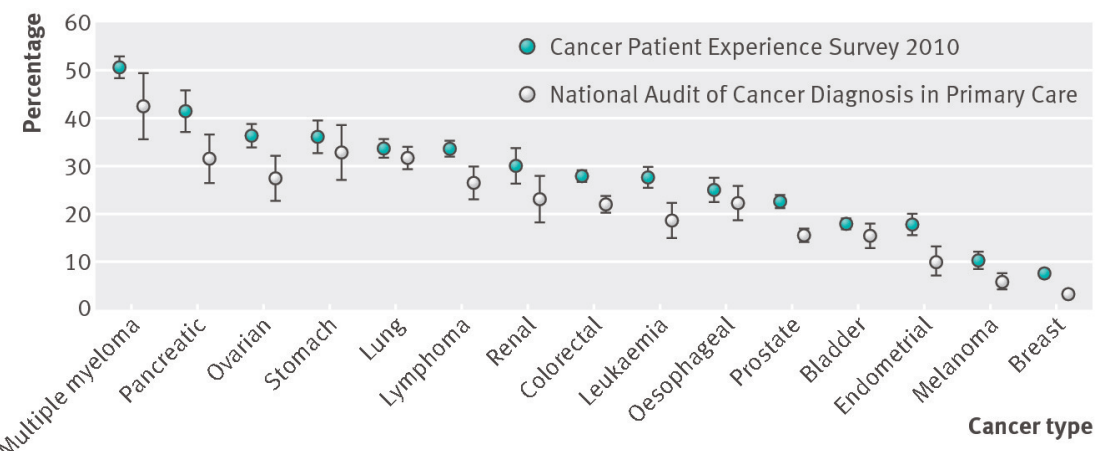

Percentage of patients with cancer who had three or more consultations with a general practitioner before referral. These data can be used to categorise cancers as "easier to suspect" (melanoma, breast, endometrial cancer), "harder to suspect" (multiple myeloma, pancreatic, ovarian, stomach, lung), or of intermediate diagnostic difficulty. Reprinted from Lyratzopoulos G, Neal RD, Barbiere JM, Rubin GP, Abel GA. Variation in number of general practitioner consultations before hospital referral for cancer: findings from the 2010 National Cancer Patient Experience Survey in England. Lancet Oncol 2012;13:353-65 with permission from Elsevier. 